\title{
An Analysis of RF Radiation on Pharmaceutical medicine at Variable Distance
}

\author{
${ }^{1}$ M. A. Othman, ${ }^{2}$ M. Z. A. A. Aziz, ${ }^{3}$ M. Sinnappa, ${ }^{4}$ M. M. Ismail, \\ ${ }^{5}$ H.A. Sulaiman, ${ }^{6}$ M. A. Meor Said, ${ }^{7}$ M. H. Misran \\ 1,2,3,4,5,6,7, Centre for Telecommunication Research and Innovation (CeTRi) Fak. Kej. Elektronik dan Kej. \\ Komputer Universiti Teknikal Malaysia Melaka
}

\begin{abstract}
In this technical paper contains the information of the Radio Frequency (RF) exposure along 10 $\mathrm{MHz}$ to $3 \mathrm{GHz}$ frequency on pharmaceutical medicine where in this testing Paracetamol were tested. The samples were prepared at five different $\mathrm{mol}(10,20,30,40 \& 50 \mathrm{ml})$ and three different distances $(5,10 \& 15$ $\mathrm{cm})$ between horn antenna and the samples. The reactions from the medicine due to RF radiation are measured at S11 by fixed distance versus varied mol. The quasi-static technique and the RF exposure results, with respective specification was included and discussed.
\end{abstract}

Keywords: Pharmaceutical medicine, mol, RF radiations, horn antenna, quasi-static

\section{INTRODUCTION}

Radio Frequency (RF) has been applied over past decade in many application and systems, and it's emerging technology in this modern world. The RF application was applied in many fields such as military, hospitality and healthcare, industrial area, transportation and logistics, sports, commercial purpose and so on as discuss in [1]. By that fact, the RF was applied in science and medical field especially in biological and pharmaceuticals such as Radio Frequency Identification (RFID), medical diathermy machines and many more. Currently, RFID tagging and tracking efforts are starting to be combined with sensor networking to provide total asset visibility [2]. In February 2004 report, the U.S Food and Drug Administration (FDA) listed Radio Frequency Identification (RFID) technology as an important tool to combat counterfeiting of pharmaceutical products [3]. The RF is allocate at within the range of $3 \mathrm{kHz}$ to $300 \mathrm{GHz}$ spectrum bandwidth. Radio Frequency (RF) radiation or well know as Electromagnetic radiation (EMR) is a form of energy exists in wave form which travels through free space medium.

Commonly, Biopharmaceuticals define as pharmaceuticals biological in nature and manufactured using biotechnology. Meanwhile, the drugs comprise other major subset of pharmaceuticals, with their source and manufacture being chemical in nature. The RFID application used to track and trace on number or code, and maintain supply chain visibility of products. By history, the RFID system is replacing the bar code technology system which has been used past years. By using RF in many application systems, the RF radiation is espoused on many biological pharmaceutical resources. For instance, RFID which used as an identification technology in many field like in shipping. Specifically, the temperature sensitive products and pharmaceutical drug knows the environmental profile of a specific shipment is an important. The information is valuable in term of product shipment and the product in market based on current real time e-pedigree which can prevent missed used or food and drugs [4]. Rather than that, the Food and Drug Administration (FDA) at United States is responsible for protect and promoting public health by regulation and supervision on food safety, dietary supplements, medications, vaccines, biopharmaceuticals, electromagnetic radiation devices and many more. FDA not allows drugs covered under Biologics License Application (BLA) and New Drug Application (NDA) [5]. Meanwhile, have a lots of encourage future research involve RF application such as Radio Frequency Identification (RFID) due to insufficient information about potential impact of RF on biologics pharmaceuticals. By doing this research and detecting every substance S11 reflection signal, the amount of reflection in decibel can estimate. Every substance and material have different reflection signal level based on combination of substance inside it. By that, the drug composite inside a pharmaceutical sample can be detected. Based on that reasons, the purpose of analyzing the RF radiation exposure on biological pharmaceuticals for RF application is to study basic properties, analyzed the characterized of RF radiation exposure and collect the response data of RF radiation on a biological pharmaceuticals sample.

\section{RADIO FREQUENCIES RADIATION}

Commonly, in the medical fields there are few common frequency range applied in most of the RF equipment or system, where these all within the range of radio frequency. In this research paper, the frequency choose base on that reasons. For instant from the $10 \mathrm{MHz}$ to $3 \mathrm{GHz}$ where is in the range of High Frequency 
(HF) to Ultra High Frequency (UHF). Radiation with lower energy level is called non-ionizing and radiation with higher energy levels called ionizing [6]. By using eight Watts of the equivalent isotropic radiated power (EIRP) is used to exposed RF radiation to test the pharmaceutical sample [7]. The EIRP used is twice than Federal Communications Commission (FCC) approved for RF application. It because, to maximized the analyze test to investigated the effect on RF radiation exposure on biological pharmaceuticals for RF application.

In order to determine the RF radiation impact of the pharmaceutical sample, the mol and the distance of RF radiation exposure is varied. The reaction of pharmaceutical sample dependents few factors such as the RF frequency, the content of mol or water, or the distance exposed to the pharmaceutical sample. Recent research have been well documented the thermal effect of RF exposure on pharmaceutical sample at varies frequency in greater detail [8]. A modified anechoic chamber is used with horn antenna to expose desire RF frequency to pharmaceutical sample according to specific mol and distance. In regards to antenna and product placement, there are two critical parameter that need to be adjusted such that the drugs are exposed to maximum possible RF power [7]. After talking measurement for all five frequencies using the spectrum analyzer, it was found that the peak power had a significant roll-off after $20 \mathrm{~cm}$ confirming the previous results of other researchers [8]. Hence, the distances between the two parallel planes have been fixed. The chamber is allocated around room temperature whereas the pharmaceutical sample place at the middle of the modified anechoic chamber. To prevent the experiment environment effect, the inter partition of anechoic chamber is fixed with solid pyramid shaped of urethane foam absorber carbon and must be closed tightly [9]. As the frequency of RF radiation signal increase, the wavelength decrease. The EIRP levels regulated by FCC won't impact the pharmaceutical sample. The paper will discussed more on the RF radiation effect according the mol and the distance varied and the Sparameter S11 will plotted.

\section{SAMPLE INFORMATION AND EXPERIMENTAL SETUP}

Paracetamol basically used to relieve the symptoms of varies pain due to headaches including migraine and the tension type headache,, colds, flu and reduce fever. Paracetamol contains an analgesic and antipyretic. Each paracetamol contained acetaminophen $650 \mathrm{mg}$. This kind of paracetamol is suitable for the adults and children above 12 years old. paracetamol reduced fever by acting on hypothalamic heat regulating to increase sweating and heat loss. With paracetamol and others drug such as alcohol will increase the risk of hepatotoxicity. The dosage for adults is 1 to 1.5 tablets for three and fours times a day, which maximally 6 tables a day. If over dosage of taken paracetamol, the sysmptoms is pallor, nausea, vomiting, loss appetite and abdominal pain, liver damage, abnormalities of glucose metabolism and metabolic acidosis, renal failure and so on. The usual treatment if taken over dosage of paracetamol is gastric lavage, maintaining fluid and electrolyte balance, and correcting hypoglycaemia. The precautions methods or problems by taking paracetamol for pregnancy and breast feeding human have not been documented. The human have the allergic to acetaminophen should not taken this tablets in any form. The Paracetamol is normally store in a dry place below $25^{\circ} \mathrm{C}$.

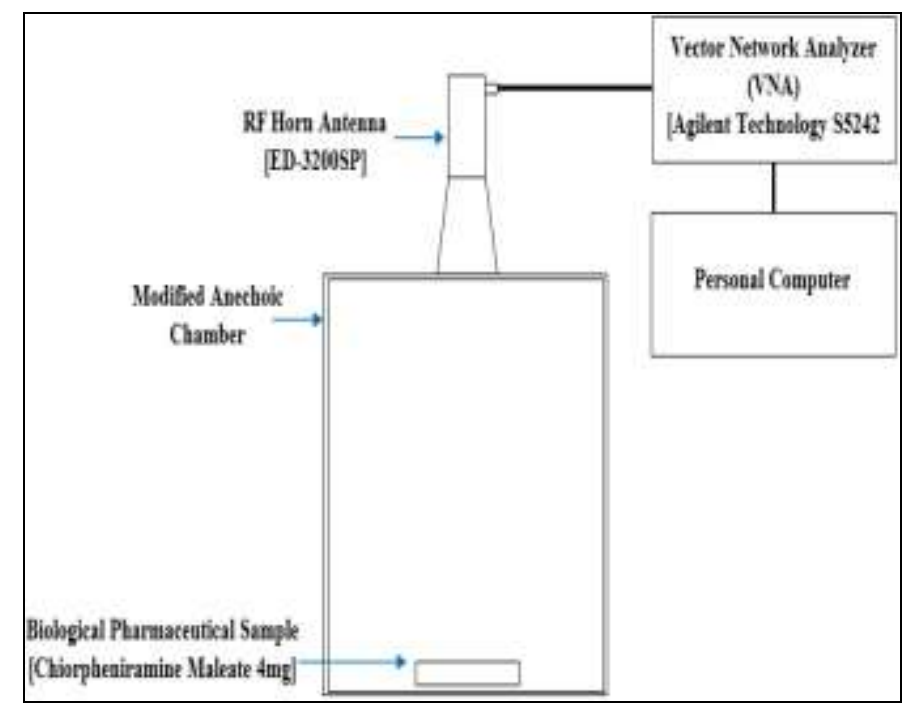

Figure 1: The diagram of the experimental setup used to generate and expose the RF signal to Paracetamol pharmaceutical sample.

Figure 1 shows, the diagram shows the experimental setup used to generate and expose the RF signal to Paracetamol pharmaceutical sample by varied the distance and the mol. The aim of the experimental setup is to generate the RF signal at desired frequency with desired power and specification to imitate as applied for RF application, with FCC united State requirement twice EIRP at output of antenna. The experimental setup follows 
a bit similar outline with one in [7] with few changes based on physical location of experimental setup needed. The modified anechoic chamber is fully closed after place the desired sample in the middle or center of the chamber and the horn antenna place at the top of the chamber. A radio frequency Anechoic Chamber is a shielded room whose walls have been covered with a material that scatter or absorbs so much of the incident energy that it can simulate free space [10].

The horn antenna is connected to Vector Network Analyzer (VNA) model Agilent Technology S5242 by using Sub-Miniature A (SMA) cable with $50 \Omega$ impedance matching. Then, the VNA is connected to personal computer for future development and analysis of the data. The modified anechoic chamber is used based on specific reasons, such as no outside RF radiation involved, rather than the supplied RF radiation. It means, the modified anechoic chamber works as RF proof from other RF radiation such as Wi-Fi, GSM and radio wave. The modified anechoic chamber is design to absorb the created RF radiation by the wall and not reflected. The horn antenna is used to exposure the RF radiation and transceiver the RF radiation signal from and to VNA. VNA is used to generate and exposure the RF radiation signal to pharmaceutical sample. The personal computer is used to save all labs testing data and using the Matlab 7.0 to simulated and plot the graph. In order to run the experiment, firstly the proper planning, schedule task and activity tables is need in conduct this type of research. Rather than that, the method of complete this task involved some hardware and software skill.

First of all, the VNA equipment has to calibrated and tested. Followed by, the cable calibration which calls electronic calibrations (ECAL) of the SMA cable that used to connect between horn antenna and the VNA equipment. By this, the cable loss can be maximally minimized and can get more accurate data. Based on previous finding, we have decide to pick a circle of $20 \mathrm{~cm}$ diameter tom place the product on the bottom plane in order to ensure at least $90 \%$ of peak $8 \mathrm{~W}$ Equivalent isotropic radiated power (EIRP) RF power is applied to all the pharmaceutical [7]. Then, S-parameter S11 of the empty modified anechoic chamber is measured for RF radiation exposure frequency range from $10 \mathrm{MHz}$ to $3 \mathrm{GHz}$ at different varied distance (centimeter). S parameter has become the most important parameter for $\mathrm{RF}$ and microwave engineering and many design methodologies have been developed around them [11]. All these data are saved accordingly in personal computer. Next, the Paracetamol pharmaceutical medicine sample is placed at middle of modified anechoic chamber without any mixing for the frequency range from $10 \mathrm{MHz}$ to $3 \mathrm{GHz}$ and each testing of $\mathrm{S} 11$ data is saved. As like previous steps, the Paracetamol pharmaceutical medicine samples with 10, 20, 30, 40 and 50 milliliter mol are mixed, and $\mathrm{RF}$ radiation exposure are tested at fixed distance and vise verse on varied distance such as 5, 10 and 15 centimeter. All the responses date is saved accordingly in personal computer. Each every single test, are taking by the average 1000 times testing mode, with 1000 step of the rage of frequency in VNA. This is because, the testing results is aim to be in high accuracy, more reliable and more precise. The quasi-static technique and the $\mathrm{RF}$ exposure results, with respective specification was included and discussed.

\section{RESULTS AND DISCUSSIONS}

There are three figures and tables in this results and discussion section. Each figure is plotted based on different of RF radiation exposure distance from Paracetamol pharmaceutical sample, such as $5 \mathrm{~cm}, 10 \mathrm{~cm}, 15 \mathrm{~cm}$, $20 \mathrm{~cm}, 25 \mathrm{~cm}, 30 \mathrm{~cm}$ and $35 \mathrm{~cm}$ distance. Besides that, for each RF radiation exposure distance from Paracetamol pharmaceutical sample will varied the mol inside the Paracetamol pharmaceutical sample by $10 \mathrm{ml}, 20 \mathrm{ml}, 30 \mathrm{ml}$, $40 \mathrm{ml}$, and 50ml. Each time testing, the original Paracetamol pharmaceutical sample without mix with any other mol are tested for each distance and it indicated as "0 $0 \mathrm{ml}$ " as show in plotted graph below. For Each testing specification, the results are measured for average 1000 times and plotted for the range $10 \mathrm{MHz}$ to $30 \mathrm{GHz}$ frequency. The linear line graph is generated from actual results which more fluctuated. This is done with Matlab 7.0 software tools with curve fitting methods where using the $10^{\text {th }}$ order polynomial and some coding. By using Matlab 7.0, the more constant and average line graph is generated by using original VNA radiation S11 data file.

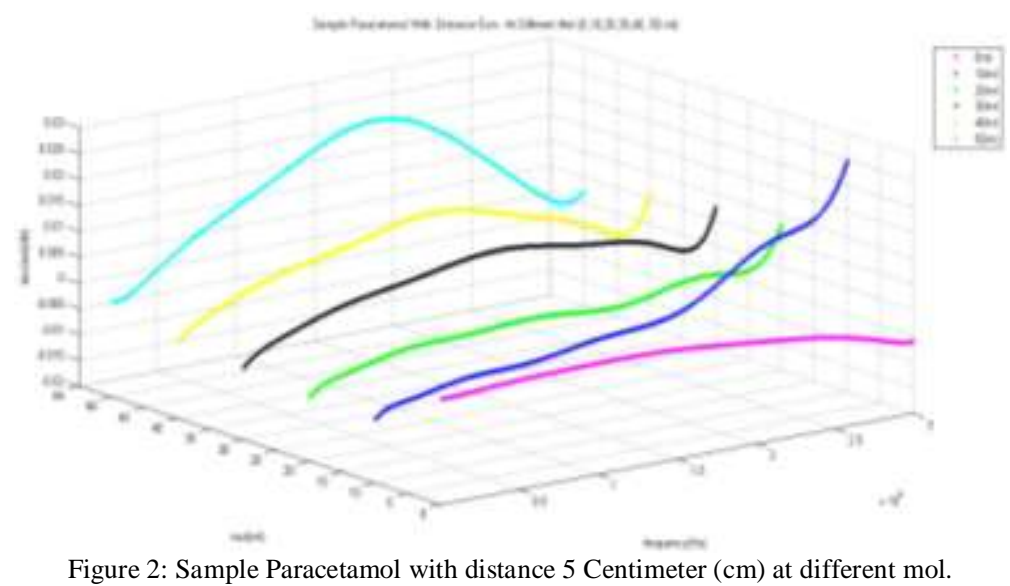

www.iosrjournals.org 
Regarding figure 2, the results show the Paracetamol pharmaceutical sample are expose to RF radiation at fixed distance $5 \mathrm{~cm}$ from horn antenna, and the mol of Paracetamol pharmaceutical sample is varied from 10ml, $20 \mathrm{ml}, 30 \mathrm{ml}, 40 \mathrm{ml}$, and $50 \mathrm{ml}$. The original Paracetamol pharmaceutical sample without mix with any other mol are tested for $5 \mathrm{~cm}$ distance along $10 \mathrm{MHz}$ to $3 \mathrm{GHz}$ frequency and it indicated as " $0 \mathrm{ml}$ ". Regarding figure 2 above, for mol $10 \mathrm{ml}$ and the $20 \mathrm{ml}$ the line graph is overall continuously increaser the along them $10 \mathrm{MHz}$ to $3 \mathrm{GHz}$ and the patter of line graph is approximately in same pattern. But for rest of the other varied mol graph, at the middle of the tested frequency around between 1.62 to $1.67 \mathrm{GHz}$, show the highest value along the tested frequency range. For the $50 \mathrm{ml}, 40 \mathrm{ml}$ and $30 \mathrm{ml}$ line graph, the maximum value of $\mathrm{S} 11$ parameter is $0.02372 \mathrm{~dB}$ at 1.665 $\mathrm{GHz}, 0.01031 \mathrm{~dB}$ at $1.62 \mathrm{GHz}$, and $0.00721 \mathrm{~dB}$ at $1.638 \mathrm{GHz}$. At the $10 \mathrm{MHz}$ frequency for 5 type varied mol $(10 \mathrm{ml}, 20 \mathrm{ml}, 30 \mathrm{ml}, 40 \mathrm{ml} \& 50 \mathrm{ml})$, the $\mathrm{S} 11$ parameter is slowly increased from $-0.007766 \mathrm{~dB}$ to $-0.001702 \mathrm{~dB}$. On the other hand, the S11 parameter at the $3 \mathrm{GHz}$ frequency is inversely decreased from $0.02468 \mathrm{~dB}$ to $0.002333 \mathrm{~dB}$. The Paracetamol pharmaceutical sample without any mixed mol are labeled as $0 \mathrm{ml}$ is have an approximately constant and stable linear line graph compare with others results. The line graph $0 \mathrm{ml}$ show a decrease at end of high frequency $3 \mathrm{GHz}$. Regarding to the table 1 below, the S11 parameter for Paracetamol pharmaceutical sample with fixed distance 5 Centimeter (cm) at frequency such as $13.6 \mathrm{MHz}, 433 \mathrm{MHz}, 868 \mathrm{MHz}, 915 \mathrm{MHz}$ and 2.4 $\mathrm{GHz}$ for each varied mol graph such as $10 \mathrm{ml}, 20 \mathrm{ml}, 30 \mathrm{ml}, 40 \mathrm{ml}$ and $50 \mathrm{ml}$ is listed detail in decibel form.

\begin{tabular}{|c|c|c|c|c|c|c|}
\hline $\begin{array}{c}\text { Frequency } \\
(\mathrm{HZ})\end{array}$ & $\mathrm{S} 11(0 \mathrm{ml}) \mathrm{dB}$ & $\mathrm{S} 11(10 \mathrm{ml}) \mathrm{dB}$ & $\mathrm{S} 11(20 \mathrm{~cm}) \mathrm{dB}$ & $\mathrm{S} 11(30 \mathrm{~cm}) \mathrm{dB}$ & $\mathrm{S} 11(40 \mathrm{~cm}) \mathrm{dB}$ & $\mathrm{S} 11(50 \mathrm{~cm}) \mathrm{dB}$ \\
\hline $13.6 \mathrm{M}$ & 0.0003818 & -0.0076594 & -0.0076454 & -0.0059978 & -0.0051649 & -0.0017139 \\
\hline $433 \mathrm{M}$ & 0.0010398 & -0.0039114 & -0.0029504 & 0.00031471 & 0.0017782 & 0.0059081 \\
\hline $868 \mathrm{M}$ & 0.0013892 & -0.0027634 & -0.0014845 & 0.0036112 & 0.0055283 & 0.013317 \\
\hline $915 \mathrm{M}$ & 0.001413 & -0.0027032 & -0.0014566 & 0.0038345 & 0.0058112 & 0.014035 \\
\hline $2.4 \mathrm{G}$ & -0.001834 & 0.010328 & 0.00090294 & 0.0042083 & 0.0045347 & 0.011498 \\
\hline
\end{tabular}

Table 1: S11 parameter in decibel for the five type frequency at Sample Paracetamol with fixed distance 5 Centimeter $(\mathrm{cm})$ and varied at different mol.

Figure 3 shows the results of Paracetamol pharmaceutical sample that are expose to RF radiation at fixed distance $10 \mathrm{~cm}$ from horn antenna, and the mol of Paracetamol pharmaceutical sample is varied from $10 \mathrm{ml}, 20 \mathrm{ml}$, $30 \mathrm{ml}, 40 \mathrm{ml}$, and $50 \mathrm{ml}$. The original Paracetamol pharmaceutical sample without mix with any other mol are tested for $10 \mathrm{~cm}$ distance along $10 \mathrm{MHz}$ to $3 \mathrm{GHz}$ frequency and it indicated as " $0 \mathrm{ml}$ ".

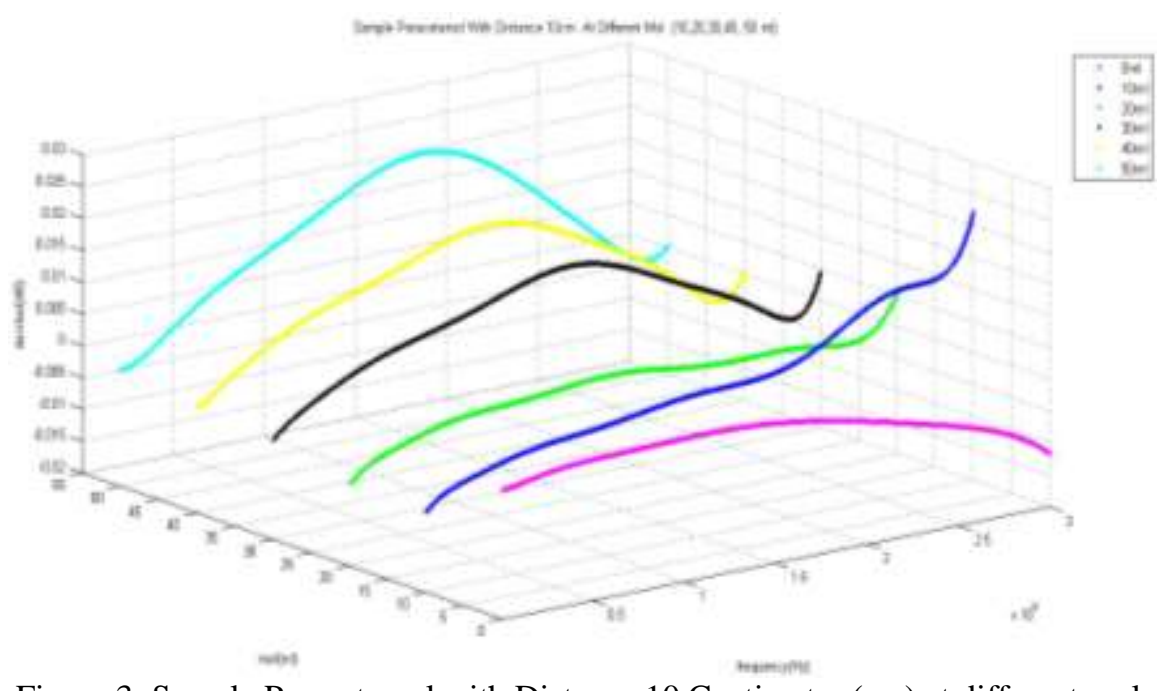

Figure 3: Sample Paracetamol with Distance 10 Centimeter $(\mathrm{cm})$ at different mol.

For the $30 \mathrm{ml}, 40 \mathrm{ml}$ and $50 \mathrm{ml}$ varied mol graph, at the middle of the tested frequency around between 1.584 to $1.62 \mathrm{GHz}$, show the highest value along the tested frequency range. The maximum value of S11 parameter for the $20 \mathrm{ml}, 30 \mathrm{ml}, 40 \mathrm{ml}$ and $50 \mathrm{ml}$ line graph is $0.01341 \mathrm{~dB}$ at $1.62 \mathrm{GHz}, 0.006629 \mathrm{~dB}$ at $1.566 \mathrm{GHz}$, $0.01584 \mathrm{~dB}$ at $1.587 \mathrm{GHz}$ and $0.02264 \mathrm{~dB}$ at $1.647 \mathrm{GHz}$. At the $10 \mathrm{MHz}$ frequency for 5 type varied mol $(10 \mathrm{ml}$, $20 \mathrm{ml}, 30 \mathrm{ml}, 40 \mathrm{ml} \& 50 \mathrm{ml}$ ), the $\mathrm{S} 11$ parameter is slowly increased from $-0.00743 \mathrm{~dB}$ to $-0.001745 \mathrm{~dB}$. Besides that, the S11 parameter at the $3 \mathrm{G} \mathrm{Hz}$ frequency is inversely decreased from $0.02201 \mathrm{~dB}$ to $0.0002996 \mathrm{~dB}$. On the other hand the sample without any mixed mol show a bit increased at stating of tested frequency and decreased at end of high frequency. Regarding to the table 2, the S11 parameter for Paracetamol pharmaceutical sample with fixed distance 10 Centimeter $(\mathrm{cm})$ at frequency such as $13.6 \mathrm{MHz}, 433 \mathrm{MHz}, 868 \mathrm{MHz}, 915 \mathrm{MHz}$ and 2.4 $\mathrm{GHz}$ for each varied mol graph such as $10 \mathrm{ml}, 20 \mathrm{ml}, 30 \mathrm{ml}, 40 \mathrm{ml}$ and $50 \mathrm{ml}$ is listed detail in decibel form. 
An Analysis of RF Radiation on Pharmaceutical medicine at Variable Distance

\begin{tabular}{|c|c|c|c|c|c|c|}
\hline $\begin{array}{c}\text { Frequency } \\
(\mathrm{HZ})\end{array}$ & $\mathrm{S} 11(0 \mathrm{ml}) \mathrm{dB}$ & $\mathrm{S} 11(10 \mathrm{ml}) \mathrm{dB}$ & $\mathrm{S} 11(20 \mathrm{~cm}) \mathrm{dB}$ & $\mathrm{S} 11(30 \mathrm{~cm}) \mathrm{dB}$ & $\mathrm{S} 11(40 \mathrm{~cm}) \mathrm{dB}$ & $\mathrm{S} 11(50 \mathrm{~cm}) \mathrm{dB}$ \\
\hline $13.6 \mathrm{M}$ & 0.0001927 & -0.0073272 & -0.0070372 & -0.004332 & -0.0034685 & -0.0017412 \\
\hline $433 \mathrm{M}$ & 0.0019802 & -0.0020161 & -0.0014892 & 0.0032417 & 0.0044731 & 0.0060816 \\
\hline $868 \mathrm{M}$ & 0.0023626 & $-2.48 \mathrm{E}-05$ & 0.000266 & 0.0074453 & 0.0094795 & 0.013055 \\
\hline $915 \mathrm{M}$ & 0.0023956 & 0.00011627 & 0.0003507 & 0.0077878 & 0.0098897 & 0.013727 \\
\hline $2.4 \mathrm{G}$ & -0.003643 & 0.010203 & -0.0001059 & 0.004861 & 0.0061058 & 0.0097541 \\
\hline
\end{tabular}

Table 2: S11 parameter in decibel for the five type frequency at Sample Paracetamol with fixed distance 10 Centimeter $(\mathrm{cm})$ and varied at different mol.

Figure 4 shows the results of Paracetamol pharmaceutical sample that are expose to RF radiation at fixed distance $15 \mathrm{~cm}$ from horn antenna, and the mol of Paracetamol pharmaceutical sample is varied from $10 \mathrm{ml}, 20 \mathrm{ml}$, $30 \mathrm{ml}, 40 \mathrm{ml}$, and $50 \mathrm{ml}$. The original Paracetamol pharmaceutical sample without mix with any other mol are tested for $15 \mathrm{~cm}$ distance along $10 \mathrm{MHz}$ to $3 \mathrm{GHz}$ frequency and it indicated as " $0 \mathrm{ml}$ ".

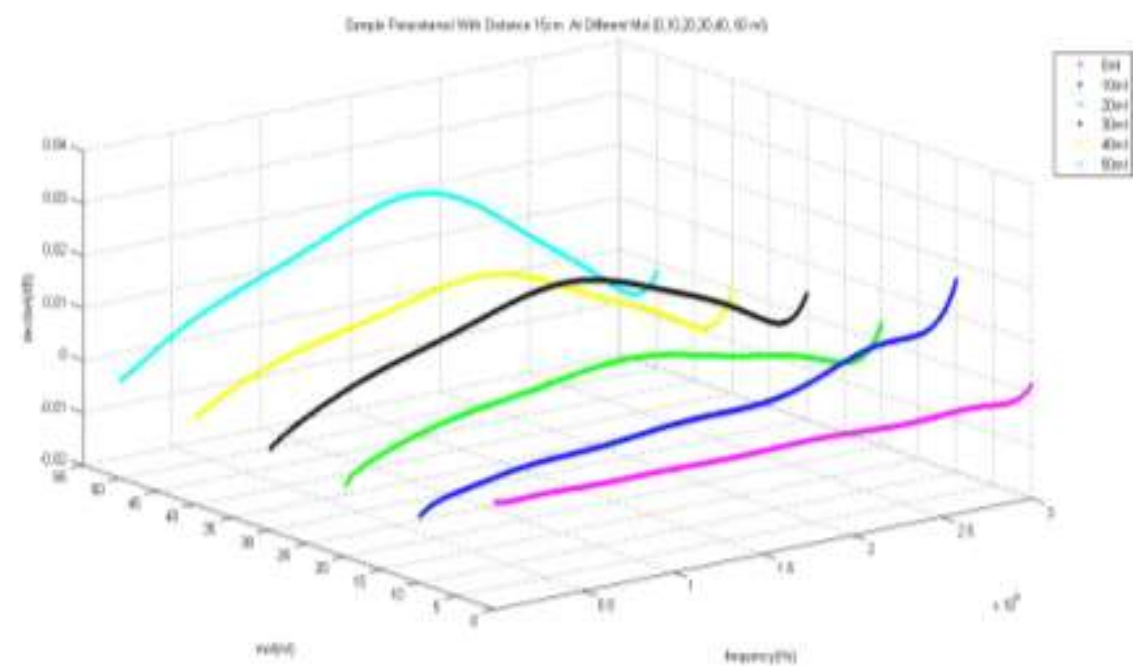

Figure 4: Sample Paracetamol with Distance 15 Centimeter $(\mathrm{cm})$ at different mol.

For the $20 \mathrm{ml}, 30 \mathrm{ml}, 40 \mathrm{ml}$ and $50 \mathrm{ml}$ varied mol graph, at the middle of the tested frequency around between 1.563 to $1.635 \mathrm{GHz}$, show the highest value along the tested frequency range. The maximum value of $\mathrm{S} 11$ parameter for the $20 \mathrm{ml}, 30 \mathrm{ml}, 40 \mathrm{ml}$ and $50 \mathrm{ml}$ line graph is $0.006629 \mathrm{~dB}$ at $1.566 \mathrm{GHz}, 0.01568 \mathrm{~dB}$ at 1.635 $\mathrm{GHz}, 0.01239 \mathrm{~dB}$ at $1.563 \mathrm{GHz}$ and $0.02264 \mathrm{~dB}$ at $1.608 \mathrm{GHz}$. At the $10 \mathrm{MHz}$ frequency for 5 type varied mol $(10 \mathrm{ml}, 20 \mathrm{ml}, 30 \mathrm{ml}, 40 \mathrm{ml} \& 50 \mathrm{ml})$, the $\mathrm{S} 11$ parameter is slowly increased from $-0.007278 \mathrm{~dB}$ to $-0.001287 \mathrm{~dB}$. Besides that, the S11 parameter at the $3 \mathrm{G} \mathrm{Hz}$ frequency is inversely decreased from $0.01666 \mathrm{~dB}$ to $-0.001531 \mathrm{~dB}$. On the other hand the sample without any mixed mol show a constant linear graph which more to negative value and bit increased at end of high frequency where both close to $0 \mathrm{~dB}$. Regarding to the table 3, the $\mathrm{S} 11$ parameter for Paracetamol pharmaceutical sample with fixed distance 15 Centimeter $(\mathrm{cm})$ at frequency such as $13.6 \mathrm{MHz}$, $433 \mathrm{MHz}, 868 \mathrm{MHz}, 915 \mathrm{MHz}$ and $2.4 \mathrm{GHz}$ for each varied mol graph such as 10ml, 20ml, 30ml, 40ml and $50 \mathrm{ml}$ is listed detail in decibel form.

\begin{tabular}{|c|c|c|c|c|c|c|}
\hline $\begin{array}{c}\text { Frequency } \\
(\mathrm{HZ})\end{array}$ & $\mathrm{S} 11(0 \mathrm{ml}) \mathrm{dB}$ & $\mathrm{S} 11(10 \mathrm{ml}) \mathrm{dB}$ & $\mathrm{S} 11(20 \mathrm{~cm}) \mathrm{dB}$ & $\mathrm{S} 11(30 \mathrm{~cm}) \mathrm{dB}$ & $\mathrm{S} 11(40 \mathrm{~cm}) \mathrm{dB}$ & $\mathrm{S} 11(50 \mathrm{~cm}) \mathrm{dB}$ \\
\hline $13.6 \mathrm{M}$ & 0.0002548 & -0.0071776 & -0.0062786 & -0.0043029 & -0.0033832 & -0.0012321 \\
\hline $433 \mathrm{M}$ & -0.000094 & -0.0028028 & 0.0005996 & 0.0037717 & 0.0035867 & 0.0077009 \\
\hline $868 \mathrm{M}$ & -0.000283 & $-1.40 \mathrm{E}-03$ & 0.0035183 & 0.0087098 & 0.0075147 & 0.013804 \\
\hline $915 \mathrm{M}$ & -0.000288 & -0.0013386 & 0.003731 & 0.0091544 & 0.0078571 & 0.014395 \\
\hline $2.4 \mathrm{G}$ & -0.000811 & 0.0058247 & 0.001552 & 0.007658 & 0.0014702 & 0.0072374 \\
\hline
\end{tabular}

Table 3: S11 parameter in decibel for the five type frequency at Sample Paracetamol with fixed distance 15 Centimeter $(\mathrm{cm})$ and varied at different mol.

\section{CONCLUSION}

In overall, as the mol $(\mathrm{ml})$ and the distance $(\mathrm{cm})$ varied increased, the $\mathrm{S} 11 \mathrm{RF}$ radiation parameters on Paracetamol pharmaceutical sample $(\mathrm{dB})$ are also decreased. In simple, the S11 RF radiation parameters on Paracetamol pharmaceutical sample $(\mathrm{dB})$ is inversely proportion to distance $(\mathrm{cm})$ and the mol $(\mathrm{ml})$ varied. It is 
significant to note that the reported biological effect occurring at low levels of RF exposure are variable, inconsistent and small in number [12]. S11 RF radiation parameters on Paracetamol pharmaceutical sample at low frequency is increased slowly and reach the maximum and start to reduced at middle of the tested frequency between 1.288 to $1.665 \mathrm{GHz}$. At beginning of tested frequency which is $10 \mathrm{MHz}$, each line graph value is increased over varied mol. Where it means, when the quantity of mol increased, the S11 RF radiation parameters on Paracetamol pharmaceutical sample is increased from the range between (-0.007766 to $0.006912 \mathrm{~dB})$, to $(-0.003568$ to $-0.001287 \mathrm{~dB})$ at fixed distances at $10 \mathrm{MHz}$. In simple, the varied mol is proportional to $\mathrm{S} 11 \mathrm{RF}$ radiation parameters at fixed distances at $10 \mathrm{MHz}$. At end of high frequency $3 \mathrm{GHz}$, each line graph at fixed distance is inversely to mol varied. Where it means, when the quantity of mol increased, the S11 RF radiation parameters on Paracetamol pharmaceutical sample at fixed distanced, is decreased from the range between $(-0.001684$ to $0.02468 \mathrm{~dB})$, to $(-0.01689$ to $0.002333 \mathrm{~dB})$. The range of the maximum value at middle of the tested frequency is from 0.0006168 to $0.02372 \mathrm{~dB}$.

\section{Acknowledgements}

First and foremost, the author would like to thanks Universiti Teknikal Malaysia Melaka, Malaysia (UTeM) for their equipment, financial and assistance support. Besides that, the authors also would like to thank the lecturers, project coordinating supervises and the technicians for their moral supports and contribution. Last but not list, the author would like to thanks those involved direct and indirect in completing this project success fully.

\section{REFERENCES}

[1] Bruce Fette, Aiello, Chandra, Dobkin (et al.), "RF \& Wireless Technologies: Know It All”, Elsevier Inc. 2008.

[2] The international committee for information technology standards (INCITS), INCITS T20 (Real Time Locating system), http://www.autoid.org/INCIT/ncits_t20_2002.htm

[3] U.S Department of Health and Human Service, Food and Drug Administration, "Combating Counterfeit Drugs: A report of food and drug", Februrary 18, 2004. http://www.fda.gov/oc/intiatiatives/counterfeit/report02_o4.html

[4] K.RothkAMN, "Evidance for a lack of DNA dauble-stand break repair in human cell exposed to very low x-ray doses", PROC. Natl. Acad. Sci. of the USA, vol. 100, pp, 5057-5062, 2003.

[5] "Uderstanding Radiation In Our World" National Safety council”, Washington DC, pp 17.

[6] Ismail Uysal..(et al.), Agriculture and Biological Engineering, Universiti of Florida, "Non-Thermal Effects of Rdio Frequency Exposure on Biologic Pharmaceuticals for RFID Application", IEEE RFID 2010.

[7] H. Bassen, S. Seidman, J. Rogul, A. Desta, and S. Wolfgang, "An exposure system for evaluating possible effects of RFID on various formulations of drug products,” Proc. IEEE Int. Conf. on RFID, pp.191-198, 2007.

[8] Ismail Uysal, Ph.D, Jean-Pierre Emond, Ph.D,University of South Florida College of Technology and Innovation, "RFID in the Pharmaceutical Supply Chain: Regulations, Physical Limitations and a Real-life Study" RFiD Journal- Ninth Anual Conference and Exhibition April 12-14 2011.

[9] Glen Dash, Ampyx LLC, "How RF Anechoic Chamber Work” Glen Dash at alum. Mit.edu, 2005 Ampyx LLC 2005.

[10] Michael Steer, "RF MICROWAVE AND RF DESIGN : A Systems Approach", SciTECH Publishing, inc., 2010, pp 288.

[11] James C. Lin, "Scientific Literature on Biological Effects of Radio Frequency Radiation: Criteria for Evaluation", IEEE Antenna's and Propagation Magazine, vol44. No. 2, April 2002. 